\title{
Peculiarities of microbial exopolysaccharide ethapolan synthesis on mixed waste oils
}

\section{Mykola Ivakhniuk, Andriy Voronenko, Tetyana Pirog}

\author{
National University of food Technologies, Kyiv, Ukraine
}

Keywords:

Acinetobacter sp.

IMV b-7005

Exopolysaccharide

Waste oils

Cultivation

Emulsification

\section{Article history:}

Received 18.12.2017

Received in revised form 21.03.2018

Accepted 29.03.2018

\section{Corresponding} author:

Mykola Ivakhniuk

E-mail:

Ivahniuk@ukr.net

DOI: $10.24263 / 2304-$

974X-2018-7-1-9

\section{Abstract}

Introduction. Possibility of the microbial exopolysaccharide (EPS) ethapolan (the producer Acinetobacter sp. IMB B-7005) synthesis intensification on the mixture of waste oils of various types and quality, as well as the emulsifying properties of that EPS, synthesized in such conditions, were studied.

Materials and methods. Cultivation of Acinetobacter sp. IMV B-7005 strain was performed in liquid medium, containing as a carbon source waste oils (sunflower, corn, olive) at concentration $5 \%, \mathrm{v} / \mathrm{v}$. EPS concentration was determined gravimetrically after precipitation with isopropanol, EPS-synthesizing ability - as a ratio of EPS concentration to biomass concentration, wich was expressed as $\mathrm{g}$ EPS / $\mathrm{g}$ biomass.

Results and discussions. Regardless of the oil type in the inoculum obtaining medium (olive or sunflower), the ethapolan synthesis indexes on the mixture of waste sunflower and olive oils (in the ratio of $1: 4 ; 4: 1 ; 1: 1$ ) were slightly lower than in conditions of the producer growth on refined sunflower oil, but at the same time increasing of the EPS-synthesizing ability on $14-41 \%$ was observed. Using mixed after frying meat, potatoes, onions and cheese sunflower oil as a substrate for the ethapolan production accompanied by the synthesis of the same polysaccharide concentration, as well as on refined oil. Reduction of the initial quantity of mixed sunflower oil to $1.25-2 \%$ with followed fractional adding in portions of $1.25-1.5 \%$ in the cultivation process to the final amount of $5 \%$ was accompanied by increase of ethapolan concentration on $15-20 \%$ compared to a one-time addition of 5\% substrate. Solutions of the synthesized under such conditions polysaccharide at concentration of $0.05 \%$ emulsified hexadecane, gasoline, diesel fuel (emulsification index $48-52 \%$ ), and the formed emulsion was stable for 20 days.

Conclusion. The results demonstrate the possibility of universal technology creating for microbial exopolysaccharide ethapolan production on mixed waste sunflower oil, regardless of the substrate type and supplier. 


\section{Introduction}

Microbial exopolysaccharides (EPS) are important class of natural polymers with different properties: the ability to change the rheological properties of aqueous systems. These biopolymers have several advantages over synthetic and plant polysaccharides: they are non-toxic and biodegradable, resistant to mechanical and oxidative degradation, temperature and low $\mathrm{pH}$ values. They are widely used in various spheres of human activity, including agriculture, textile, chemical (household chemicals) and in the food industries. As mainly EPS are characterized by low toxicity, they are also used in the pharmaceutical industry: as bases for ointments, liniments or as thickeners for syrups $[1,2]$.

The analyzed foreign and domestic literature shows that despite the long study of microbial EPS (more than 50 years) and widespread use in various fields - expensive carbohydrates (glucose, sucrose, starch) remain the main substrate for their production [3], and there are only some reports about EPS synthesis on industrial waste.

In 2017, in accessible literature, the work about xanthan synthesis $(6.46 \mathrm{~g} / \mathrm{l})$ by the strain Xanthomonas campestris LRELP-1 on a medium containing $50 \mathrm{ml}$ of food residues hydrolyzate (500 $\mathrm{g}$ of waste was mixed with 1 liter of $1.5 \% \mathrm{H}_{2} \mathrm{SO}_{4}$ and filtered out) from the Shanghai University dining room appeared [4]. In the work [5], using of rice straw hydrolyzate, previously treated with $\mathrm{NaOH}$ at $100^{\circ} \mathrm{C}$, as an alternative source of carbon for the xanthan synthesis by $X$. campestris PTCC 1473 was studied. Under using such substrate, the yield of the product was 8.6-9.36 g EPS / $100 \mathrm{~g}$ substrate, and its properties were practically the same compared with the xanthan of Sigma-Aldrich firm, the USA. Drakou et al investigated the synthesis of EPS by the Pseudomonas aeruginosa LVD-10 and Enterobacter sp. SW strains on non-carbohydrate substrates [6]. Under Pseudomonas aeruginosa LVD-10 and Enterobacter sp. SW cultivation on technical glycerin $(4.5 \%, \mathrm{v} / \mathrm{v})$, the amount of synthesized polysaccharide was 3.2 and $2.5 \mathrm{~g} / \mathrm{l}$, respectively, under undiluted sewage using in quantity of $100 \mathrm{ml}$, LVD-10 strain synthesized $1.3 \mathrm{~g} / \mathrm{l}$, where as SW only $0.7 \mathrm{~g} / 1[6]$.

In our previous studies [7] the possibility of the microbial polysaccharide ehtapolan synthesis under its producer Acinetobacter sp. IMV B-7005 cultivation on medium with 5\% of waste after frying meat or potatoes sunflower oil was shown. Later, in order to expand the raw material base for this EPS synthesis, as a substrate, waste corn, olive and rapeseed oils were used [8]. However, on factories that process plant raw materials or in catering establishments, oils of different types and after frying various products are mixed together without separation.

Proceeding from the foregoing, the purpose of this work is to investigate the ability of Acinetobacter sp. IMV B-7005 to synthesize ethapolan on a mixture of different types of waste oils.

\section{Materials and methods}

\section{Object of research}

The EPS-synthesized strain of bacteria Acinetobacter sp. 12S, which is deposited in the Depository of Institute of Microbiology and Virology, National Academy of Sciences of Ukraine by the number of IMV B-7005 was used as the object of research. 


\section{Cultivation conditions}

Cultivation of Acinetobacter sp. IMV B-7005 was carried out in a liquid mineral medium of such composition (g/l): $\mathrm{KH}_{2} \mathrm{PO}_{4}-6.8 ; \mathrm{KOH}-0.9 ; \mathrm{MgSO}_{4} \times 7 \mathrm{H}_{2} \mathrm{O}-0.4$; $\mathrm{CaCl}_{2} \times 2 \mathrm{H}_{2} \mathrm{O}-0.1 ; \mathrm{NH}_{4} \mathrm{NO}_{3}-0.6 ; \mathrm{FeSO}_{4} \times 7 \mathrm{H}_{2} \mathrm{O}-0.001$.

The following types of oils were used as a source of carbon and energy, in the quantity of $5 \%(\mathrm{v} / \mathrm{v})$ :

- Refined: sunflower (TM "Oleina", Ukraine), olive of cold press (TM «Salvadori», Italy), corn (LLC «Kama» Ukraine);

- Waste: sunflower after frying meat (from the McDonald's network, Kyiv, Ukraine), corn after frying meat, olive after frying potatoes or meat (obtained at home after threetimes frying for 20 minutes), mixed sunflower oil after frying meat, potatoes, onions, cheese (obtained from fast-food restaurants "RockerPub" Kyiv, Ukraine). $1[9]$.

The content of poly- and monounsaturated fatty acids in used oils is presented in Table

\section{Characteristics of vegetable oils used as a substrate}

Table 1

\begin{tabular}{|c|c|c|}
\hline \multirow{2}{*}{ Oils } & \multicolumn{2}{|c|}{ Content of fatty acids (\% of the total mass) } \\
\cline { 2 - 3 } & Polyunsaturated & Monounsaturated \\
\hline Sunflower & 60 & 33 \\
\hline Corn & 54 & 27 \\
\hline Olive & 12 & 87 \\
\hline
\end{tabular}

In some variants, sunflower and olive oil were added into the medium in a ratio of $4: 1$; $1: 4$ and $1: 1$. In one research, the initial concentration of mixed oil was reduced to $1.25-2 \%$, and further it was brought to a final concentration $5 \%$ in portions $1.25-1.5 \%$ in the process of cultivation.

In additionally yeast autolysate $(0.5 \%, \mathrm{v} / \mathrm{v})$ and multivitamin complex "Complevit" $(0.00095 \%)$ were added to the medium as growth promoter and source of pantothenate, respectively.

Culture from the exponential phase, grown in the medium with $0.5 \%(\mathrm{v} / \mathrm{v})$ of refined (sunflower, olive or corn oil) or waste oil (sunflower after frying meat, olive or corn after frying potatoes) was used as the inoculum. Quantity of inoculum was $10 \%$ from the volume of the medium. Cultivation of Acinetobacter sp. IMV B-7005 was carried out in flasks $(750 \mathrm{ml})$ with $100 \mathrm{ml}$ of medium in shacker $(320 \mathrm{rpm})$ at $30{ }^{\circ} \mathrm{C}$ for 120 hours.

\section{Indicators of growth and of the target product synthesis}

Biomass concentration was determined by optical density of the cell suspension with the following recalculation on the absolutely dry biomass according to the calibration curve. Quantity of synthesized ethapolan was determined gravimetrically. For this, 1.5-2 volumes of isopropanol were added to a certain amount of culture liquid (usually 10-15 $\mathrm{ml}$ ), the precipitate of EPS was washed by clean isopropyl alcohol and dried at room 
temperature for $24 \mathrm{~h}$. EPS-synthesizing ability was determined as the ratio of the EPS concentration to the concentration of biomass and was expressed in $\mathrm{g}$ EPS/g biomass.

\section{Emulsifying properties of ethapolan}

The emulsifying properties were determined for $0.05 \%$ (for polysaccharide) culture fluid solutions and $0.05 \%$ ethapolan solutions. Ethopolan was isolated from the culture liquid by isopropanol deposition followed by washing of the EPS precipitate in a pure organic solvent and drying at room temperature for 24 hours.

Determination of the emulsifying properties (emulsification index, $\mathrm{E}_{24}, \%$ ) was carried out as follows: $2 \mathrm{ml}$ of $0.05 \%$ culture liquid solution or ethapolan solution were added with $2 \mathrm{ml}$ of emulsifying substrate (hexadecane, gasoline, diesel fuel) and shaken for 2 minutes. Measurement of the emulsification index was carried out in 24 hours as the ratio of the emulsion layer height to the total fluid height in the test tube and expressed as a percentage.

The formed emulsions were stored for 20 days at room temperature to check its stability.

\section{Statistical analysis}

Statistical analysis of experimental data were performed according to Lakin [10]. The results of the experiment in accordance with the Student t-test were statistically significant at the $5 \%$ significance level.

\section{Results and discussions}

In previous studies [7] for the synthesis of polysaccharide ethapolan on the waste oils (sunflower, corn, olive, rapeseed), inoculum was grown on the corresponding refined substrate. However, using of waste oils for inoculum obtaining is more appropriate both from an environmental and technological points of view. Therefore, at the first stage of the study, the synthesis of ethapolan was investigated with using waste oil as a carbon source for both inoculum preparation and EPS biosynthesis. In these experiments different types of waste oils for inoculum production and EPS biosynthesis (Table 2) were used in order to develop a universal technology of ethapolan synthesis independent of the oil quality and supplier.

Experiments have shown that the replacement of sunflower, olive, corn oils with the appropriate waste one in medium for inoculum obtaining was accompanied by decrease on $7-17 \%$ of ethapolan concentration synthesized on the olive after frying potato and meat and corn after frying meat oils (see Table 2).

Considering the obtained results, the refined oil was used for inoculum preparation in the following studies.

As a rule, in catering establishments and enterprises of plant raw materials processing, oil-containing wastes are mixed before utilization. Consequently, it was advisable to investigate the synthesis of polysaccharide ethapolan on mixed oils of different types after frying certain products.

Since sunflower oil is traditionally used for frying in Ukraine and also olive oil has become more and more popular in recent years, on the next stage the synthesis of strain IMV B-7005 EPS on a mixture of these substrates was investigated (Table 3). 
Table 2

Ethapolan synthesis depending on the inoculum preparation

\begin{tabular}{|c|c|c|c|}
\hline \multicolumn{2}{|c|}{ Oil in the medium for } & \multirow{2}{*}{$\begin{array}{l}\text { EPS, \% from } \\
\text { control }\end{array}$} & \multirow{2}{*}{$\begin{array}{l}\text { EPS-synthesizing ability, \% } \\
\text { from control }\end{array}$} \\
\hline EPS biosynthesis & $\begin{array}{l}\text { Inoculum } \\
\text { obtaining }\end{array}$ & & \\
\hline \multirow{2}{*}{$\begin{array}{l}\text { Olive after potatoes } \\
\text { frying }\end{array}$} & $\begin{array}{c}\text { Sunflower after } \\
\text { meat frying }\end{array}$ & 81,3 & 66,7 \\
\hline & Sunflower refined & 93,8 & 112,8 \\
\hline \multirow{2}{*}{$\begin{array}{l}\text { Corn after meat } \\
\text { frying }\end{array}$} & $\begin{array}{c}\text { Olive after } \\
\text { potatoes frying }\end{array}$ & 79,6 & 69,4 \\
\hline & Olive refined & 65,6 & 63,9 \\
\hline \multirow{2}{*}{$\begin{array}{l}\text { Olive after meat } \\
\text { frying }\end{array}$} & $\begin{array}{l}\text { Corn after potatoes } \\
\text { frying }\end{array}$ & 80,9 & 72,5 \\
\hline & Corn refined & 97,1 & 60,0 \\
\hline
\end{tabular}

Note: 1. Control $(100 \%)$ - indexes of the ethapolan synthesis under inoculum obtaining on the corresponding refined oil.

2. In the synthesis rates determining, the error did not exceed $5 \%$.

Table 3

Indexes of the ethapolan synthesis on the mixture of waste oils

\begin{tabular}{|c|c|c|c|}
\hline \multicolumn{2}{|c|}{ Oil in the medium for } & \multirow{2}{*}{$\begin{array}{c}\text { EPS,\% from } \\
\text { control } \\
\text { inoculum } \\
\text { obtaining }\end{array}$} & $\begin{array}{c}\text { EPS biosynthesis } \\
\text { EPnthesizing ability, \% } \\
\text { from control }\end{array}$ \\
\hline \multirow{4}{*}{$\begin{array}{c}\text { Sunflower } \\
\text { refined }\end{array}$} & $\begin{array}{c}\text { Olive + sunflower } \\
(1: 4)\end{array}$ & 80,8 & 136,1 \\
\cline { 2 - 3 } & $\begin{array}{c}\text { Olive + sunflower } \\
(4: 1)\end{array}$ & 69,3 & 122,2 \\
\cline { 2 - 3 } & $\begin{array}{c}\text { Olive + sunflower } \\
(1: 1)\end{array}$ & 76,9 & 141,7 \\
\cline { 2 - 3 } & $\begin{array}{c}\text { Mixed sunflower } \\
\text { oil }\end{array}$ & 107,7 & 130,6 \\
\hline \multirow{4}{*}{ Olive refined } & $\begin{array}{c}\text { Olive + sunflower } \\
(1: 4)\end{array}$ & 85,1 & 134,3 \\
\cline { 2 - 3 } & $\begin{array}{c}\text { Olive + sunflower } \\
(4: 1)\end{array}$ & 68,7 & 114,3 \\
\cline { 2 - 3 } & $\begin{array}{c}\text { Olive + sunflower } \\
(1: 1)\end{array}$ & 62,7 & 128,6 \\
\cline { 2 - 3 } & $\begin{array}{c}\text { Mixed sunflower } \\
\text { oil }\end{array}$ & 95,5 & 91,4 \\
\hline
\end{tabular}

Note: 1 . Control $(100 \%)$ - indexes of the ethapolan synthesis under strain Acinetobacter sp. IMV B7005 cultivation on refined oil.

2. In the synthesis rates determining, the error did not exceed $5 \%$. 
Experiments have shown that under Acinetobacter sp. IMV B-7005 cultivation on a mixture of sunflower and olive oils in any ratio, reduction of ethapolan concentration was observed, but at the same time, the EPS-synthesizing ability increased in $14-41 \%$ compared with those on refined sunflower oil. Data about using mixed sunflower oil as a substrate for the EPS biosynthesis are noteworthy: regardless of the oil type used for the inoculum preparation (refined sunflower or olive), the concentration of the synthesized ethapolan was practically the same as under producer cultivation on refined oil, which makes use of such substrate promising in the development of highly efficient EPS technology.

The waste oil contains a large amount of toxic substances (acrolein, acrylamide, lipid peroxides) [11] and addes into the Acinetobacter sp. IMV B-7005 cultivation medium in high concentration $(5 \%)$, which may be the reason of low rates of ethapolan synthesis. Therefore, in order to reduce the content of these toxic substances, the initial concentration of oil in the cultivation medium of the IMV B-7005 strain was reduced, with following fractional substrate application during cultivation to a final concentration of $5 \%$. This approach is used in biotechnology to reduce the duration of the lag phase, as well as the intensification of microbial technologies [12].

For example, the initial concentration of glucose in the cultivation medium of Agrobacterium sp. ATCC 31749 (producer of EPS curdlan) was $30 \mathrm{~g} / \mathrm{l}$ and $\mathrm{NH}_{4} \mathrm{Cl}-0.5 \mathrm{~g} / \mathrm{l}$. During the first 14 hours of cultivation, the sources of carbon and nitrogen were added into the medium to the final concentration 119 and $3.6 \mathrm{~g} / \mathrm{l}$, respectively. Under such conditions, the concentration of polysaccharide was $72 \mathrm{~g} / \mathrm{l}$, which in 2 times more than under one time substrate adding [13]. Hyun Mi Kim et al [14] investigated the effect of fed-batch fermentation on the synthesis of Ganoderma resinaceum DG-6556 EPS. The initial concentration of glucose in the medium was $10 \mathrm{~g} / \mathrm{l}$, at 6 days of cultivation $50 \mathrm{~g} / \mathrm{l}$ of glucose were added additionally, which made it possible to increase the amount of synthesized polysaccharide to $4.6 \mathrm{~g} / \mathrm{l}$. In cultivation medium of Tremella mesenterica NRRL Y- 6158 $20 \mathrm{~g} / \mathrm{l}$ of glucose were added fractionally at interval of $50 \mathrm{~h}$. durring 7 days. Under such conditions, the producer synthesized $9.9 \mathrm{~g} / 1$ of polysaccharide, which in 2.2 times more than under one-time adding of the substrate [15]. The fractional adding of milk whey into the cultivation medium of Lactobacillus kefiranofaciens JCM 6985, producer of EPS kefiran, was accompanied by increase of the synthesized polysaccharide concentration almost in 2 times (to $2514 \pm 93 \mathrm{mg} / \mathrm{l}$ ), compared to the one-time substrate addition [16]. Concentration of EPS, synthesized by marine bacteria Zunongwangia profunda SM-A87 on milk whey with a fractional adding of this substrate into $5 \mathrm{~L}$ fermenter reached $17.2 \mathrm{~g} / \mathrm{l}$ [17].

Our experiments have shown that reducing of initial concentration of oil in the Acinetobacter sp. IMV B-7005 cultivation medium to $1.25-2 \%$, with following substrate fractional addition to the final concentration of $5 \%$, contributed to increase of synthesized ethapolan amount to $15-20 \%$ compared to a one-time addition of $5 \%$ of the substrate.

The practical value of microbial exopolysaccharides is determined primarily by their ability in small concentrations to change the rheological properties of water systems - to increase viscosity, to form gels, to exhibit emulsifying and suspending properties in water systems. Thanks to these properties, EPS can be used as emulsifiers in the food and pharmaceutical industries, cosmetology. Increasingly, exopolysaccharides are found in solving the problems of secondary oil production due to its high viscosity, pseudoplasty, resistance to high pressure and temperature [12].

Today the following microbial EPS are the most promising in the world for using in oil extraction: xanthan (producer Xanthomonas campestris) and scleroglucan (producer Sclerotium glucanicum). It should be noted that ethapolan solutions are characterized by 
unique emulsifying properties that are not inherent to most known microbial polysaccharides, including xanthan, due to its acylated polysaccharide which containes fatty acids $\left(\mathrm{C}_{10}-\mathrm{C}_{18}\right)$ [12]. The lipophilic part in the ethapolan molecule provides formation of a stable emulsion of water with oil and other hydrocarbons. Nowadays, only one such polysaccharide as emulsant (producer Acinetobacter calcoaceticus RAG-1) in which fatty acids are attached to the carbohydrate chain via of ethereal bonds has been studied in sufficient quantity [18]. Due to the presence of fatty acids in its composition emulsan is a great emulsifier.

Taking into account the above, the emulsifying properties with hydrophobic substrates such as hexadecane, gasoline and diesel fuel of the ethapolan, synthesized on mixed waste oils, were investigated at the next stage of the work. Precipitated and dried polysaccharide was used in the studies, since such product form is the most popular on the polymer market.

However, the unique feature of the domestic polysaccharide is practically confirmed possibility of its using in the form of post-fermentation culture fluid in the technology of oil production [12]. Excluding the stages of target product precipitation and drying in industrial production of EPS ensures a significant reduction in the cost of the product, as well as the preservation of the polysaccharide properties. Using such form of ethapolan has an additional advantage, since polysaccharides are stabilized with ingredients that are the part of the culture fluid. Therefore, the emulsifying properties were investigated also for the strain IMV B-7005 culture fluid containing ethapolan.

Studies have shown that, regardless of the marketable type of the ethapolan solutions, the emulsification indexes for all substrates were practically the same (48-52\%, Fig. 1).

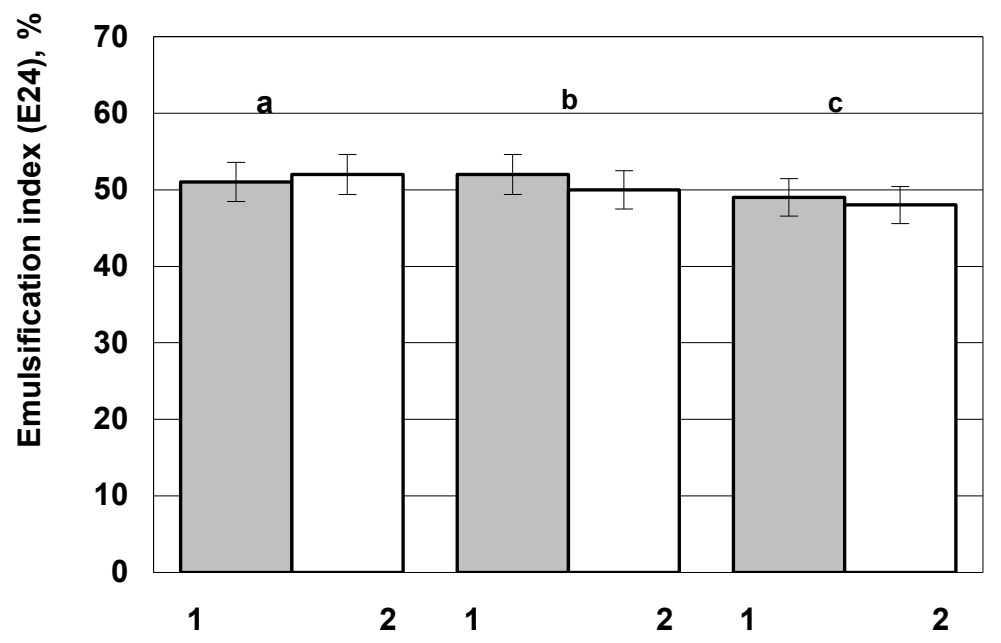

Figure 1. Emulsification index of the ethapolan solutions obtained on the mixed waste oil:

Substrate for emulsification: $\mathrm{a}$ - hexadecane, $\mathrm{b}$ - diesel fuel, $\mathrm{c}-$ gasoline.

Emulsifier: $1-0,05 \%$ solution of ethapolan, $2-0,05 \%$ (for polysaccharide) solution of strain IMB B-7005 culture fluid.

An important feature of polysaccharides is not only the ability to form gels, suspensions or emulsions with different substrates, but also to ensure the stability 
(preservation of initial properties) of these two-phase systems for a long time of storage. The formed emulsiones of ethapolan with hexadecane, gasoline and diesel fuel were stored for 20 days, the emulsification index decrease didn't exceede 5\%.

It is known from the literature, that the formed emulsion of hexadecane with emulsan (at a concentration of $1 \mathrm{mg} / \mathrm{ml}$ ) was kept for 4 days within the $\mathrm{pH}$ range of 4-8 [19]. The EPS synthesized by Enterobacter cloaceae at concentration of $1 \mathrm{mg} / \mathrm{ml}$ is capable to form an emulsion with a wide range of hydrophobic substrates, with a shelf life of emulsions not more than 10 days [19]. According to the authors, the emulsifying properties of this polysaccharide are provided by the proteins included in its composition, but their low thermostability makes it impossible to use this EPS under elevated temperatures. Though, liposan produced by Candida lipolytica did not exhibit significant surface-active properties, it emulsified various hydrocarbons and oils at $8 \mathrm{mg} / \mathrm{ml}$ of hydrocarbon. These emulsions were stable only for $50 \mathrm{~min}$. Thus, ethapolan has a great advantages over other EPS used as emulsifiers, that makes the strain IMV B-7005 polysaccharide promising for use in various technologies [19].

\section{Conclusions}

Thus, as a result of this work, the possibility of different types of waste oils using, including mixed, for the synthesis of the microbial polysaccharide ethapolan was shown for the first time. The obtained results testify the possibility of a "flexible" and versatile technology developing for obtaining this EPS with stable emulsifying and rheological properties, that does not depend on the quality of the oil (its nature and the product that was heated), the region and the supplier of raw materials.

\section{References}

1. Moscovici M. (2015), Present and future medical applications of microbial exopolysaccharides, Frontiers in Microbiology, 6, DOI: 10.3389/fmicb.2015.01012

2. Madhuri1 K. V., Prabhakar V. K. (2014), Microbial exopolysaccharides: Biosynthesis and potential applications, Oriental Journal of Chemistry, 30(3), pp. 1401-1410, http://dx.doi.org/10.13005/ojc/300362

3. Roca C., Alves V.D., Freitas F., Reis M.A. (2015), Exopolysacchrides enriched in rare sugars: bacterial sources, production, and applications, Frontiers in Microbiology, 6, DOI: 10.3389/fmicb.2015.00288.

4. $\quad$ Li P., Zeng Y., Xie Y., Li X., Kang Y., Wang Y., Xie T., Zhang Y. (2017), Effect of pretreatment on the enzymatic hydrolysis of kitchen waste for xanthan production, Bioresource Technology, pp. 84-90, http://dx.doi.org /10.1016/j. biortech.2016.10.035

5. Jazini M. H., Fereydounia E, Karimiab K. (2017), Microbial xanthan gum production from alkalipretreated rice straw, Royal Science of Chemistry Advances, 7, pp. 35073514, DOI: $10.1039 / \mathrm{c} 6 \mathrm{ra} 26185 \mathrm{j}$.

6. Drakou E.M., Amorim C. L., Castro P. M. L., Panagiotou F., Vyrides I. (2017), Wastewater valorization by pure bacterial cultures to extracellular polymeric substances (EPS) with high emulsifying potential and flocculation activities, Waste biomass valorization, DOI: 10.1007/s12649-017-0016-9

7. Ivakhniuk M.O., Pirog T.P. (2015). Vplyv sposobu pidhotovky posivnoho materialu 
na syntez polisakharydu etapolanu na oliyevmisnykh substratakh, Naukovi pratsi NUHT, 21(5), pp. 17-21

8. Ivakhniuk N.A., Voronenko A.A., Pirog T.P. (2017), Mikrobnyi sintez ekzopolisakharida etapolana na razlichnykh vidakh otrabotannykh rastitelnykh masel, Izvestiia Natsionalnoi akademii nauk Belarusi. Seriia biologicheskikh nauk, 2, pp. $87-93$

9. Obukhova L.A., Garagulia E.B. (2016), Rastitelnye masla v pitanii. Sravnitelnyi analiz, Available at: http://www.argo-shop.com.ua/article-9182.html

10. Lakin G.F. (1990), Biometriia, Vysshaia shkola, Moskow.

11. Guillén M. D., Uriarte P. S. (2012), Aldehydes contained in edible oils of a very different nature after prolonged heating at frying temperature: Presence of toxic oxygenated $\alpha, \beta$ unsaturated aldehydes, Food Chemistry, 131, pp. 915-926, DOI:10.1016/j.foodchem.2011.09.079.

12. Pidhors'kyy V.S., Iutyns'ka H.O., Pirog T.P. (2010), Intensyfikatsiya tekhnolohiy mikrobnoho syntezu, Naukova dumka, Kyiv.

13. Pirog T.P., Antoniuk M.M., Skrotska O.I., Kihel N.F. (2016), Kharchova biotekhnolohiia, Vydavnytstvo Lira-K, Kyiv.

14. Hyun Mi Kim, Soon-Young Paik, Kyung Soo Ra, Kwang Bon Koo, Jong Won Yun, Jang Won Choi (2006), Enhanced production of Exopolysaccharides by fed-batch culture of Ganoderma resinaceum DG-6556, Microbiology, 44(2), pp. 233-242

15. Baets S. De., Laing S. Du., Francois C., Vandamme E.J. (2002), Optimization of exopolysaccharide production by Tremella mesenterica NRRL Y-6158 through implementation of fed-batch fermentation, Journal of Industrial Microbiology \& Biotechnology, 29, pp. 181-184

16. Cheirsilp B., Suksawang S., Yeesang J., Boonsawang P. (2018), Co-production of functional exopolysaccharides and lactic acid by Lactobacillus kefiranofaciens originated from fermented milk, kefir, Journal of Food Science and Technology, 55(1), pp. 331-340, DOI: 10.1007/s13197-017-2943-7

17. Sun M.L., Liu S.B., Qiao L.P., Chen X.L., Pang X., Shi M., Zhang X.Y., Qin Q.L., Zhou B.C., Zhang Y.Z., Xie B.B. (2014), A novel exopolysaccharide from deep-sea bacterium Zunongwangia profunda SM-A87: low-cost fermentation, moisture retention, and antioxidant activities, Applied Microbiology and Biotechnology, 98(17), pp. 7437-7445, DOI: 10.1007/s00253-014-5839-8

18. Panilaitis B., Castro G.R., Solaiman D., Kaplan D.L. (2007), Biosynthesis of emulsan biopolymers from agro-based feedstocks, Journal of Applied Microbiology, 102(2), pp. 531-537, DOI: 10.1111/j.1365-2672.2006.03078.x

19. Iyer A., Mody K., Jha B. (2006), Emulsifying properties of a marine bacterial exopolysaccharide, Enzyme and Microbial Technology, 38, pp. 220-222. 